\title{
Microbial Safety and Shelf Life of UV-C Treated Freshly Squeezed White Grape Juice
}

\author{
Sevcan Unluturk and Mehmet R. Atilgan
}

\begin{abstract}
The effects of UV-C irradiation on the inactivation of Escherichia coli K-12 (ATCC 25253), a surrogate of E. coli $\mathrm{O} 157: \mathrm{H7}$, and on the shelf life of freshly squeezed turbid white grape juice (FSWGJ) were investigated. FSWGJ samples were processed at $0.90 \mathrm{~mL} / \mathrm{s}$ for $32 \mathrm{~min}$ by circulating 8 times in an annular flow UV system. The UV exposure time was $244 \mathrm{~s}$ per cycle. The population of $E$. coli $\mathrm{K}-12$ was reduced by $5.34 \mathrm{log}$ cycles after exposure to a total UV dosage of $9.92 \mathrm{~J} / \mathrm{cm}^{2}\left(1.24 \mathrm{~J} / \mathrm{cm}^{2}\right.$ per cycle) at $0.90 \mathrm{~mL} / \mathrm{s}$ flow rate. The microbial shelf life of UV-C treated FSWGJ was extended up to $14 \mathrm{~d}$ at $4{ }^{\circ} \mathrm{C}$. UV exposure was not found to alter $\mathrm{pH}$, total soluble solid, and titratable acidity of juice. There was a significant effect $(P<0.05)$ on turbidity, absorbance coefficient, color, and ascorbic acid content. Furthermore, all physicochemical properties were altered during refrigerated storage. The microbial shelf life of FSWGJ was doubled after UV-C treatment, whereas the quality of juice was adversely affected similarly observed in the control samples.
\end{abstract}

Keywords: food safety, food quality, juice, non-thermal processing, shelf life

Practical Applications: UV-C irradiation is a non-thermal method used for processing of fruit juices with a minimal or no changes in flavor, essential nutrients, and vitamins. Fresh grape juice is a popular drink, usually consumed at summer time due to many beneficial health effects. Although thermal pasteurization is widely used for extending the shelf life of fruit juices, it causes a "cook taste" in grape juice. The applicability of UV-C irradiation as an alternative to thermal pasteurization was investigated. It is concluded that UV-C treatment can be used for extending the shelf life of fresh grape juice.

\section{Introduction}

The demand for high quality fruit juice and fruit juice type beverages has markedly expanded in recent years because of consumer attention to quality, value, safety, and health. Grape and grape juice contains antioxidants. The inhibition of low-density lipoprotein oxidation, and thus lowering the cholesterol in human blood may be due to the antioxidant effect of grape juice (Frankel and others 1998). Freshly squeezed fruit juices have shelf life of maximum 5 to $6 \mathrm{~d}$. They are usually packed and delivered to retailers within $24 \mathrm{~h}$. The shelf life of juices depends on a variety of factors such as the type of product, the ingredients (water, sugar content), acidity, storage period, and storage temperature. Freshly squeezed juice has a shorter shelf life than pasteurized juice and must be kept chilled. The US FDA (2000) criteria for fruit and vegetable juice processing is a 5 -log reduction in the number of the target pathogen of concern. Thermal treatment is an effective method for extending the shelf life of juice products. However, it also results in the deterioration of many quality and nutritional attributes. The change of color and loss of essential aroma and vitamins were reported during thermal pasteurization of fruit juices (Choi and Nielsen 2005; Lee and Coates 2003; Mazzotta 2001).

There has been a recent increase in the demand for minimally processed, high-quality fruit juices. However, it is difficult to ensure product safety without using conventional thermal preser-

MS 20150403 Submitted 3/10/2015, Accepted 5/28/2015. Authors Unluturk and Atilgan are with Dept. of Food Engineering, Izmir Inst. of Technology, Urla, Izmir, 35430, Turkey. Direct inquiries to author Unluturk (E-mail: sevcanunluturk@iyte.edu.tr). vation methods (Heinz and others 2003; Mertens and Knorr 1992). Non-thermal preservation methods, such as pulsed electric field (PEF), high hydrostatic pressure (HHP), ultrasound (US), and short wave ultraviolet irradiation (UV-C), have been shown to be potentially applicable for producing high-quality juice (Daoudi and others 2002; Heinz and others 2003; Pala and Toklucu 2013b; Patil and others 2009; Tikekar and others 2011; Tiwari and others 2009). Of these, UV-C processing holds potential to be a low-cost technology (Koutchma 2009).

UV-C irradiation as a fruit juice preservation method has been extensively studied (Keyser and others 2008; Pala and Toklucu 2013a and b; Tran and Farid 2004). The germicidal effect of UV-C light (200 to $280 \mathrm{~nm}$ range) on pathogens and spoilage microorganisms, including yeasts, molds, and lactic acid bacteria (LAB) in fruit juices, were cited in many studies (Caminiti and others 2012; Franz and others 2009; Fredericks and others 2011; Gabriel and Nakano 2009; Guerrero-Beltrán and others 2009; Pala and Toklucu 2013a, 2013b).

The objective of this research was to study the effects of UV$\mathrm{C}$ irradiation on the inactivation of Escherichia coli K-12 (ATCC 25253), a surrogate of E. coli O157:H7, by means of a newly designed annular flow UV system, and the shelf life of UV-C irradiated freshly squeezed turbid white grape juice (FSWGJ). The microbial stability of UV-C treated and untreated (control) FSWGJ was examined during the storage period at $4{ }^{\circ} \mathrm{C}$. Additionally, the changes in physicochemical properties of grape juice, such as absorbance coefficient, turbidity, color, total soluble solids ( $\left.{ }^{\circ} \mathrm{Brix}\right), \mathrm{pH}$, and vitamin $\mathrm{C}$ content and titratable acidity, were determined after UV-C irradiation and during storage. 


\section{Materials and Methods}

\section{Grape juice preparation}

For the production of freshly squeezed juice, white grapes of the Sultana variety ( $V$. vinifera) were purchased from a local supermarket (Tesco-Kipa) in Izmir, Turkey. A household table top fruit juice extractor (Frutti Pro XL, Moulinex, France) was used to extract the grape juice. The juice was strained twice to eliminate most of the solid particles coming from grape's skin. Lascorbic acid (400 mg/L; Merck, Darmstadt, Germany) was added as an antioxidant to maintain the original color of the juice during the preparation stage. Grapes are high in tartaric acid, and potassium bitartrate crystals are precipitated in grape juice during cold storage. To prevent this bitartrate instability from occurring in bottled juice, a cold stabilization is usually performed on single-strength juice (Alongi and others 2010). Potassium bitartrate particles formed in white grape juice were precipitated by shaking at $100 \mathrm{RPM}$ and $4{ }^{\circ} \mathrm{C}$ for 2 to $3 \mathrm{~h}$ in the shaker (Thermo Electron Corp., Ohio, U.S.A.). Following the straining and removal of the bitartrates, juice samples were stored in $500 \mathrm{~mL}$ sterile bottles and frozen at $-18{ }^{\circ} \mathrm{C}$ for up to $3 \mathrm{mo}$. Since experimental studies take some time to be completed, freezing was necessary to have homogenous samples. It was also useful for the fast removal of potassium bitartrate crystals from the juice.

\section{UV processing equipment and UV-C treatment}

The schematic diagram of an annular UV system is shown in Figure 1. The UV system was constructed in the Food Engineering Dept. at Izmir Inst. of Technology, İzmir, Turkey. UV system was
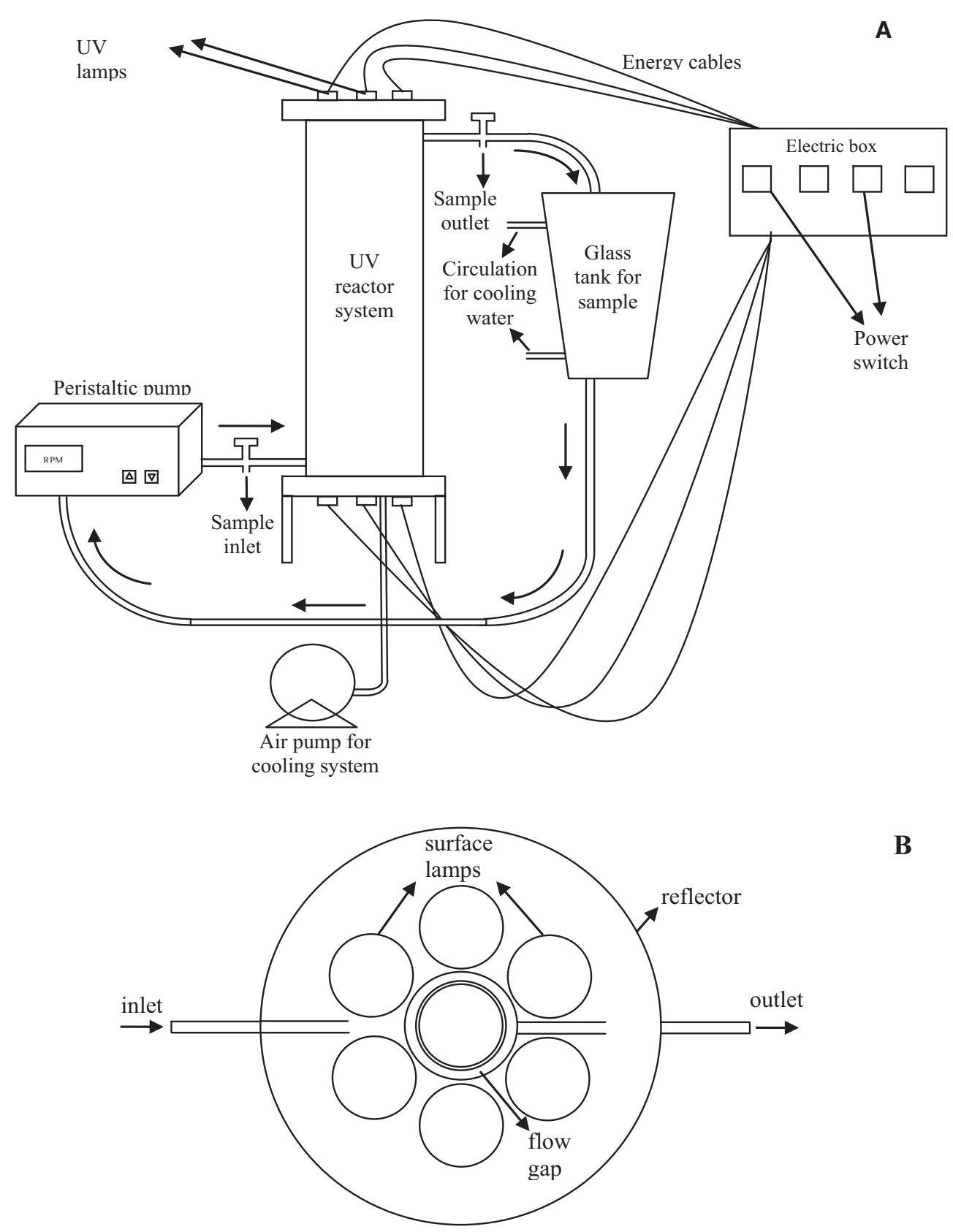
Table 1-Physicochemical and optical properties of FSWGJ before and after UV treatment and at the end of storage.

\begin{tabular}{|c|c|c|c|c|}
\hline \multirow[b]{2}{*}{$\mathrm{pH}$} & \multicolumn{2}{|c|}{ Day 0} & \multicolumn{2}{|c|}{ Day 14} \\
\hline & Untreated & Treated & Untreated & Treated \\
\hline & $3.955 \pm 0.01$ & $3.94 \pm 0.00$ & $3.64 \pm 0.02^{\mathrm{c}}$ & $3.78 \pm 0.01^{\mathrm{b}}$ \\
\hline Turbidity (NTU) & $98.22 \pm 3.00$ & $118.75 \pm 2.47^{\mathrm{a}}$ & $228.75 \pm 3.89^{c}$ & $348.75 \pm 13.79^{\mathrm{b}}$ \\
\hline Abs coeff. $\left(\mathrm{cm}^{-1}\right)$ & $12.13 \pm 1.78$ & $7.69 \pm 0.16^{\mathrm{a}}$ & $9.58 \pm 0.08^{c}$ & $12.95 \pm 3.58^{\mathrm{b}}$ \\
\hline$L^{*}$ & $27.74 \pm 0.08$ & $26.48 \pm 0.15^{\mathrm{a}}$ & $24,51 \pm 0.06^{c}$ & $25,54 \pm 0.15^{\mathrm{b}}$ \\
\hline$a^{*}$ & $0.05 \pm 0.02$ & $0.40 \pm 0.01^{\mathrm{a}}$ & $2.34 \pm 0.05^{c}$ & $1.85 \pm 0.06^{\mathrm{b}}$ \\
\hline$b^{*}$ & $2.98 \pm 0.03$ & $4.60 \pm 0.05^{\mathrm{a}}$ & $6.84 \pm 0.07^{c}$ & $6.58 \pm 0.02^{\mathrm{b}}$ \\
\hline BI & $11.10 \pm 0.12$ & $19.55 \pm 0.0^{\mathrm{a}}$ & $38.75 \pm 0.13^{c}$ & $34.19 \pm 0.05^{\mathrm{b}}$ \\
\hline${ }^{\circ} \mathrm{Brix}$ & $18.57 \pm 0.13$ & $18.23 \pm 0.02$ & $16.79 \pm 0.03^{c}$ & $17.08 \pm 0.06^{\mathrm{b}}$ \\
\hline Ascorbic acid (g/L of juice) & $0.56 \pm 0.03$ & $0.01 \pm 0.00^{\mathrm{a}}$ & $0.000^{\mathrm{c}}$ & $0.000^{\mathrm{b}}$ \\
\hline Titratable acid $(\%)$ & $0.209 \pm 0.007$ & $0.216 \pm 0.004$ & $0.906 \pm 0.053^{c}$ & $0.536 \pm 0.028^{\mathrm{b}}$ \\
\hline
\end{tabular}

Results were presented as means \pm standard error" $(n=2)$. Column values with different letters $(\mathrm{a}, \mathrm{b}, \mathrm{c})$ differ $(P<0.05)$.

asignificant change between untreated and UV treated samples $(P<0.05)$.

${ }^{\mathrm{b}}$ Significant change between UV treated samples at day 0 and day $14(P<0.05)$.

${ }^{\mathrm{c}}$ Significant change between untreated samples at day 0 and day $14(P<0.05)$.

composed of an annular tube made from quartz glass and equipped ters of UV tube were 3 and $4 \mathrm{~cm}$, respectively. The flow gap was with a cylindrical reflector (Afe Olgunlar Inc., Izmir, Turkey) and $5 \mathrm{~mm}$ and the height of UV tube was $40 \mathrm{~cm}$. Heat accumulaseven $254 \mathrm{~nm}$ low pressure mercury UV lamps (15 W total power, tion caused by UV lamps was removed from the reactor by an model XX-15S; UVP Inc., Cambridge, England). One UV lamp air pump compressor (KNF Inc., Freiburg, Germany). The glass was installed at the center of the system, whereas the remaining sample tank with a cooling unit (Guven Cam, Ankara, Turkey) lamps were placed around the outer cylinder of the quartz tube was integrated into the UV reactor to control the temperature of at an equivalent distance (Figure 1). The inner and outer diame- irradiated liquid, keeping the temperature of FSWGJ samples at 24

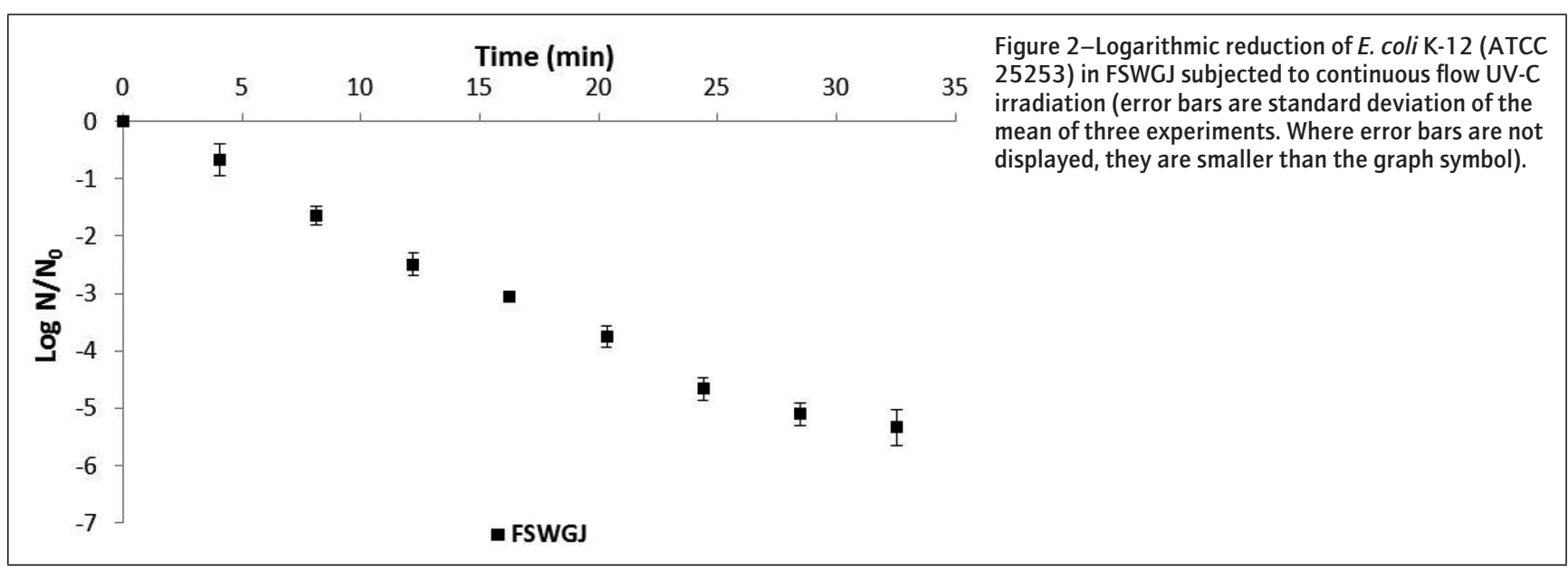

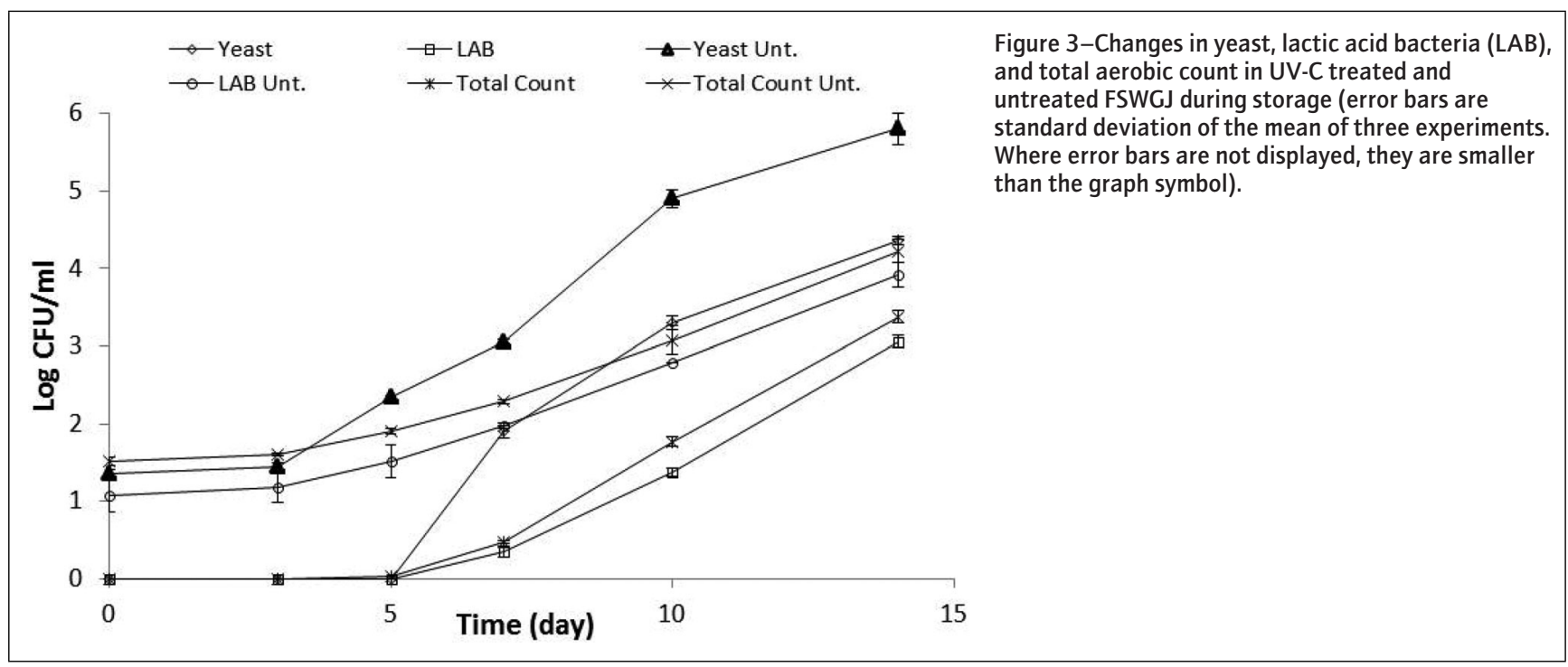


to $25{ }^{\circ} \mathrm{C}$ during processing. Juice samples in $500 \mathrm{~mL}$ volumes were pumped through the $5 \mathrm{~mm}$ annular space of the UV reactor, using a peristaltic pump (Watson Marlow Inc., Cornwall, England). The residence time that the grape juice in the UV reactor was recorded manually as $244 \mathrm{~s}$. The flow rate was $0.90 \mathrm{~mL} / \mathrm{s}$. FSWGJ samples were processed at the lowest flow rate as possible and circulated eight times in the annular flow UV system in order to achieve 5 $\log$ reductions in the number of target microorganisms, as required for juice pasteurization by FDA. The fluid flow was laminar and Re number was estimated as 291 (Bird and others 2002). The total UV exposure time of FSWGJ samples was $32.5 \mathrm{~min}$.

Samples for microbial analysis were taken by using glass sample taps after each cycle. The survival curve of E. coli $\mathrm{K}-12$ was drawn by plotting $\log \left(N / N_{0}\right)$ reductions versus time (min). The juice samples used in the shelf life study were treated with UV-C irradiation under the same conditions.

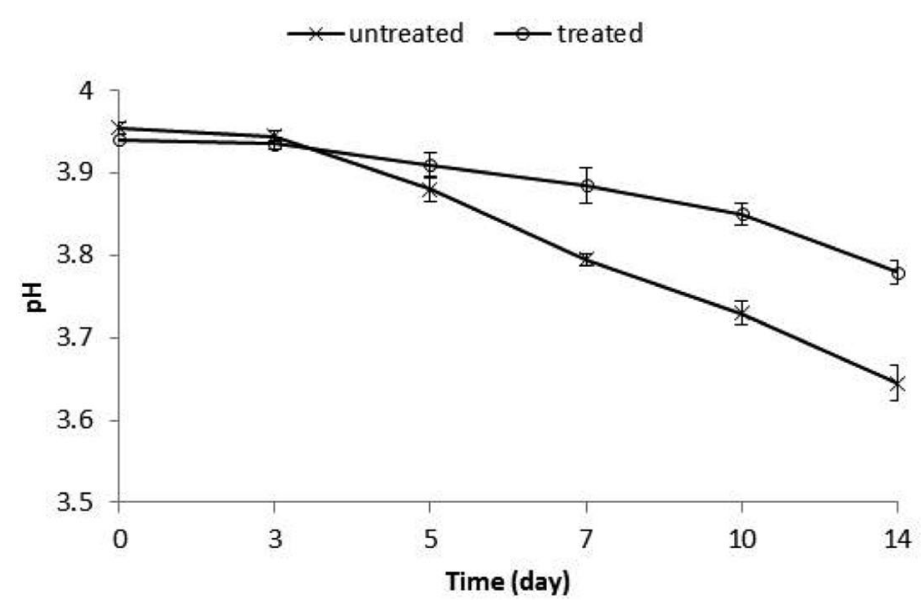

A

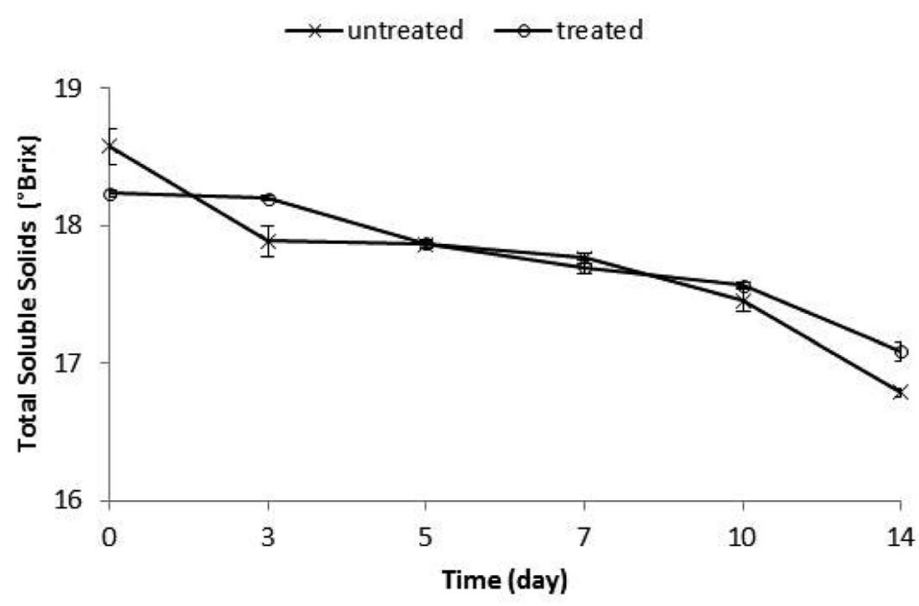

B

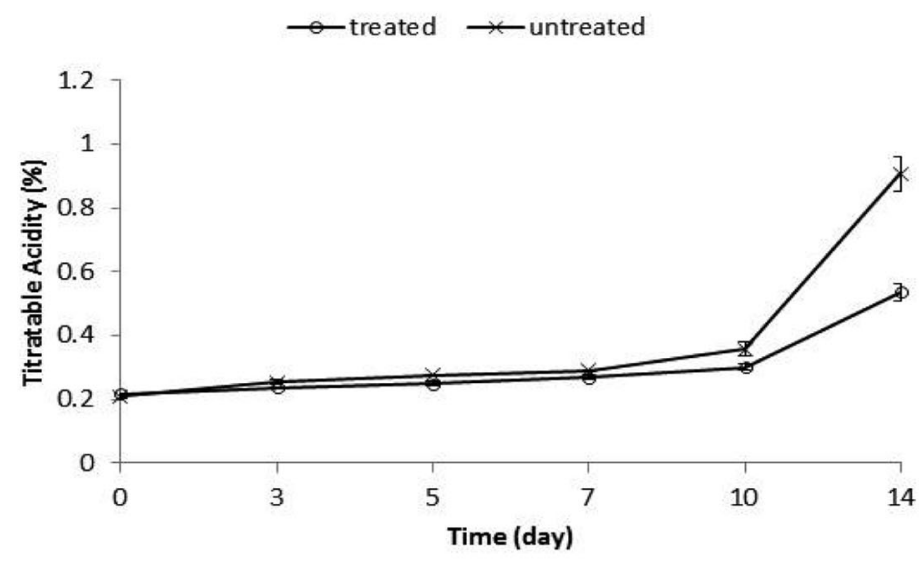

C
Figure 4-Changes in (A) pH (B) Total soluble content ( ${ }^{\circ}$ Brix) and (C) titratable acidity (\%) of UV-C treated and untreated FSWGJ during storage at $4{ }^{\circ} \mathrm{C}$ for $14 \mathrm{~d}$ (error bars are standard deviation of the mean of three experiments. Where error bars are not displayed, they are smaller than the graph symbol). 


\section{UV intensity measurement by using iodide/iodate} actinometrical method

The ultraviolet light intensity emitted by the lamps was determined by using the technique proposed by Rhan (1997). A 0.6 M potassium iodide (Merck)/0.1 M of potassium iodate (Merck) solution in $0.01 \mathrm{M}$ borate buffer ( $\mathrm{pH} 9.25$ ) (Merck) was used as a chemical actinometer. Irradiation of this solution resulted in the linear formation of triiodide, which was quantified by measuring its absorbance at $352 \mathrm{~nm}$ for each dose of irradiation (Cielo and others 2010). The number of einsteins of photons absorbed by the irradiated sample were estimated from the moles of generated triiodide (Rahn 1997). For this purpose, $500 \mathrm{~mL}$ of iodide/iodate solution was UV irradiated in the continuous flow UV reactor by recycling 8 times. During UV irradiation, samples were collected from each cycle at the exit of the UV system and its absorbance was immediately recorded using a UV-visible spectrophotometer (Carry 100; Varian Inc., Calif., U.S.A.) set at a wavelength $352 \mathrm{~nm}$. The UV intensity was estimated from Eq. (1) as described in Rahn
(1997) and Rahn and others (2003, 2006).

$$
\begin{aligned}
\mathrm{UV} \text { Incident Intensity }\left(I_{0}, \mathrm{~W} / \mathrm{cm}^{2}\right) & =\frac{\text { incidentjoules }}{\text { area } * \mathrm{UV} \text { time }(\mathrm{s})} \\
& =\frac{\text { UVfluence }}{\text { area }}
\end{aligned}
$$

where area and UV time were the surface area of the annular gap $\left(502.65 \mathrm{~cm}^{2}\right)$ and the UV exposure time per cycle $(244 \mathrm{~s})$. UV intensity $\left(I_{\mathrm{o}}\right)$ was estimated as $13 \pm 0.2 \mathrm{~mW} / \mathrm{cm}^{2}$ from the Eq. (1).

In order to determine the average UV intensity $\left(I_{\text {avg }}\right)$ absorbed by grape juice samples while passing from the UV system, BeerLambert law was integrated over the sample depth (Morowitz 1950):

$$
I_{\text {avg }}=I_{0}\left(1-e^{-A_{\mathrm{e}} \gamma}\right) / A_{\mathrm{e}} \gamma
$$

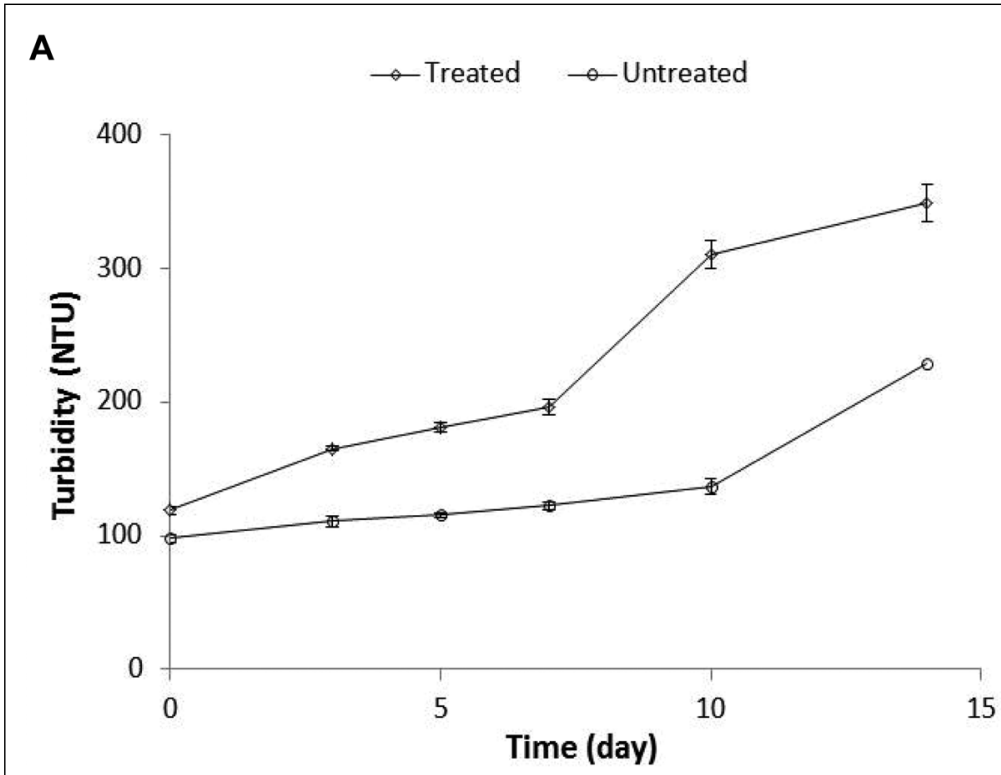

B

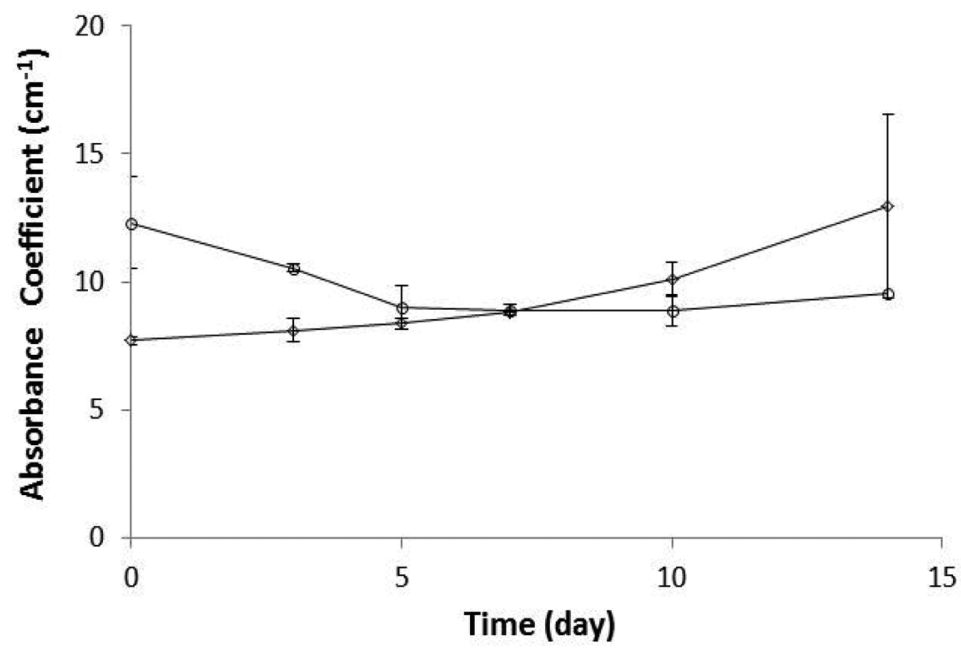

Figure 5-Changes in (A) turbidity and (B) absorbance coefficient of UV-C treated and untreated FSWGJ during storage at $4{ }^{\circ} \mathrm{C}$ for $14 \mathrm{~d}$ (error bars are standard deviation of the mean of three experiments. Where error bars are not displayed, they are smaller than the graph symbol). 
where $I_{\mathrm{O}}$ is the incident intensity $\left(\mathrm{mW} / \mathrm{cm}^{2}\right)$ estimated from the actinometrical method, $A_{\mathrm{e}}$ is the absorbance coefficient $\left(12.13 \mathrm{~cm}^{-1}\right)$ and $\gamma$ is the path length $(0.5 \mathrm{~cm})$. The average UV intensity was estimated as $5.1 \pm 2.8 \mathrm{~mW} / \mathrm{cm}^{2}$. UV dose was calculated using $I_{\text {avg }}$ by Eq. (3):

$$
d=t * \mathrm{I}_{\mathrm{ave}}
$$

where $d$ represents $\mathrm{UV}$ dose $\left(\mathrm{mJ} / \mathrm{cm}^{2}\right), t$ is the exposure time $(\mathrm{s})$, and $I_{\text {ave }}$ refers to average intensity $\left(\mathrm{mW} / \mathrm{cm}^{2}\right)$. All experiments were done in triplicate. Based on the procedure, it was found that
$1.24 \mathrm{~J} / \mathrm{cm}^{2}$ of UV dose per cycle was absorbed by the grape juice samples in the UV system.

Microbiological analyses for the inactivation and shelf life studies

Inactivation study. In the inactivation study, the aim was to evaluate the effectiveness of UV-C irradiation on the target pathogenic microorganism under predetermined processing conditions. For this purpose, E. coli K-12 (ATCC 25253), a surrogate of E. coli O157:H7, was used as a target microorganism for the inoculation of FSWGJ. E. coli K-12 (ATCC 25253) was

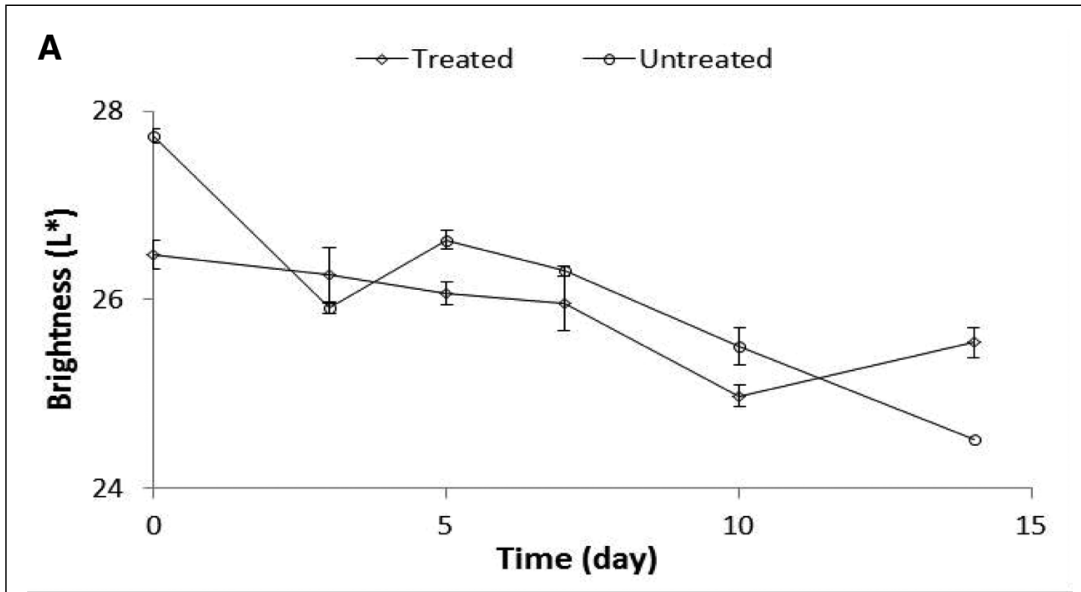

Figure 6-Changes in (A) brightness- $L^{*}$, (B) redness-greenness- $a^{*}$, and

(C) yellowness-blueness- $b^{*}$ of UV-C treated and untreated FSWGJ during storage at $4{ }^{\circ} \mathrm{C}$ for $14 \mathrm{~d}$ (error bars are standard deviation of the mean of three experiments. Where error bars are not displayed, they are smaller than the graph symbol).
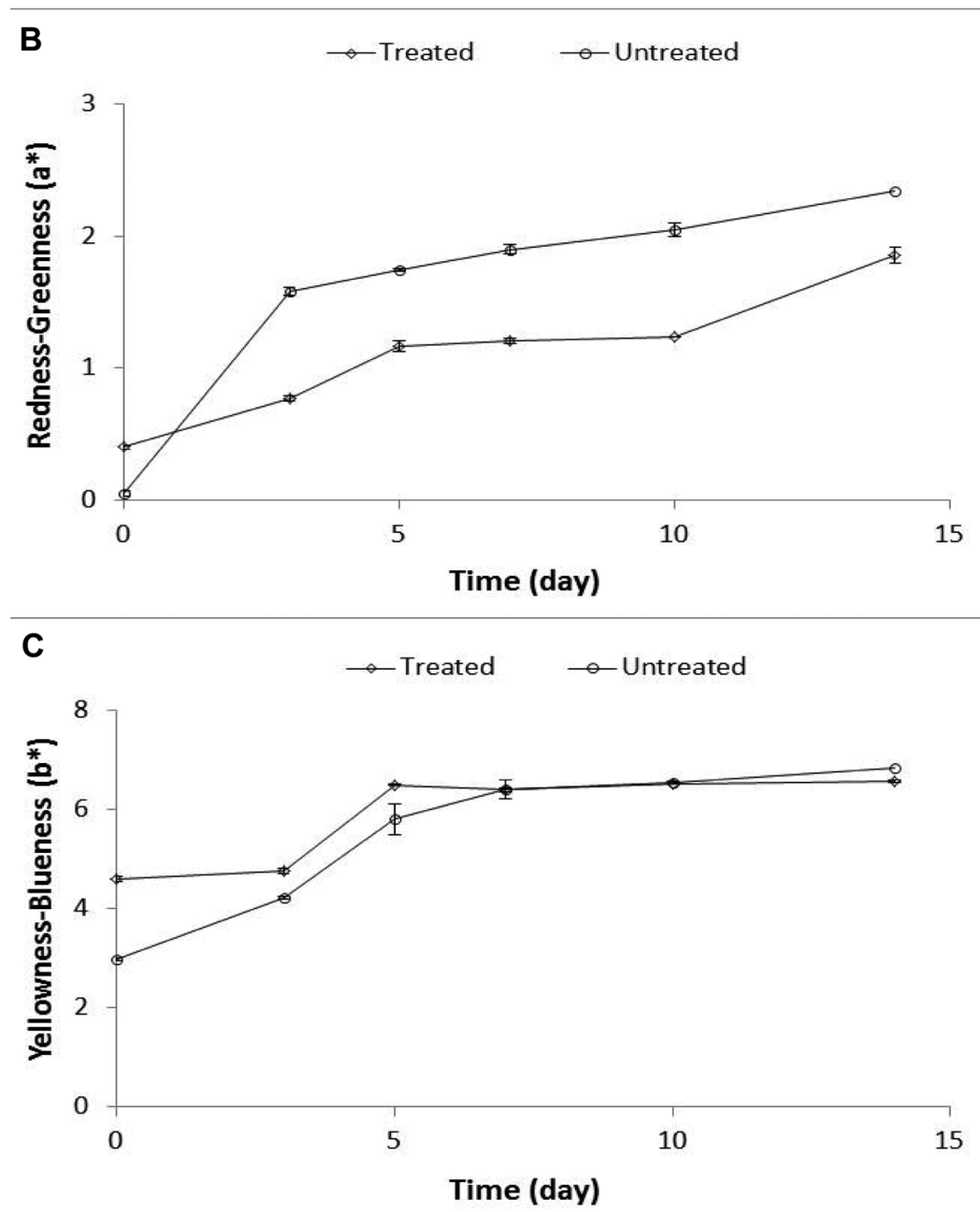
cultured from $-80{ }^{\circ} \mathrm{C}$ lyophilized vials. A broth subculture was enriched after inoculation of a loopful from the stock culture into a test tube containing nutrient broth (NB; Merck) and incubated overnight (18 to $24 \mathrm{~h}$ ) at $37{ }^{\circ} \mathrm{C}$ (Unluturk and others 2010). E. coli K-12 (ATCC 25253) culture was first adapted to $\mathrm{pH} 4$ using tartaric acid, following the steps described in Pala and Toklucu (2013b). After acid adaptation, a single colony was transferred to $100 \mathrm{~mL}$ of tryptic soy broth (TSB; Merck) supplemented with $0.75 \%(\mathrm{w} / \mathrm{v})$ glucose (Merck) and then incubated at $37{ }^{\circ} \mathrm{C}$ for overnight. $100 \mathrm{~mL}$ of enriched TSB broth was centrifuged at $3000 \times \mathrm{g}$ for $5 \mathrm{~min}$ and harvested cells were directly added to $500 \mathrm{~mL}$ of grape juice, achieving a final concentration of about $8.689 \pm 0.078 \log \mathrm{CFU} / \mathrm{mL}$ (Unluturk and Atilgan 2014). Enumeration of E. coli K-12 (ATCC 25253) was performed on tryptic soy agar (TSA; Difco Corp., Franklin Lakes, NJ, U.S.A.) using appropriate dilutions with phosphate buffered peptone solution at $37{ }^{\circ} \mathrm{C}$ for $18 \mathrm{~h}$. FSWGJ was pasteurized at $72{ }^{\circ} \mathrm{C}$ for $20 \mathrm{~s}$ using a water bath prior to inoculation. For this purpose, $250 \mathrm{~mL}$ conical flasks containing juice $(100 \mathrm{~mL})$ were placed in a water bath (Precisdig Model; JP Selecta S.A., Barcelona, Spain) and held for $20 \mathrm{~s}$ at $72{ }^{\circ} \mathrm{C}$. The temperature was checked by $\mathrm{K}$ type thermocouples (CEM DT-8891E, Shenzhen, China), placed into the center of samples. The grape juice samples were continuously stirred to maintain homogeneous temperature distribution during heating. Following the heat treatment, samples were immediately placed into ice-bath for cooling prior to analysis. After pasteurization, $0.1-\mathrm{mL}$ samples were immediately surface plated on TSA and Potato Dextrose Agar (PDA; Merck) to check the background flora of pasteurized juice samples. Thermal processing was able to eliminate all the background flora of FSWGJ.

In order to determine the possible inactivation due to acidic environment of the grape juice, the acid adapted culture prepared in TSB, with $\mathrm{pH}$ adjusted to 4.0 and 3.6, was tested by inoculating into grape juice (Pala and Toklucu, 2013b). Acid adapted TSB broth samples were centrifuged at $3000 \mathrm{xg}$ for $5 \mathrm{~min}$ at $4{ }^{\circ} \mathrm{C}$. Cells were inoculated to $100 \mathrm{~mL}$ of FSWGJ with initial concentration of $10^{7-8} \mathrm{CFU} / \mathrm{mL}$. Inoculated grape juice was incubated at $37^{\circ} \mathrm{C}$ for $24 \mathrm{~h}$ and enumerated after 2, 4, 6, 7, 10, and $24 \mathrm{~h}$ on TSA (Unluturk and Atilgan, 2014).

Shelf life study. Frozen samples were first thawed and then filtered. Some samples were subjected to UV-C irradiation, while others were left untreated (controls). UV-C treated and untreated grape juices were aseptically filled into sterile bottles and stored at $4{ }^{\circ} \mathrm{C}$ for $14 \mathrm{~d}$. Samples were periodically taken during storage period for microbial analysis. Microorganisms in the samples were enumerated. A small sample was placed on a slide, gram stained and examined at $400 \times$ and $1000 \times$ magnification under a microscope (Olympus CX31; Olympus Corp., Tokyo, Japan) equipped with digital camera system (Olympus DP25). The microscopic examination of the background flora revealed that the microorganisms mainly consisted of yeasts and LAB.

Spoilage yeasts were enumerated on PDA by incubating at $25^{\circ} \mathrm{C}$ for $5 \mathrm{~d}$. LAB was counted on De Man Rogosa and Sharp Agar (MRS; Merck) using pour-plate method after incubation at $30^{\circ} \mathrm{C}$ for $2 \mathrm{~d}$. The total aerobic count was carried out by spread plating on TSA at $37^{\circ} \mathrm{C}$ for $24 \mathrm{~h}$ (Unluturk and Atilgan, 2014).

\section{Physicochemical properties of FSWG}

Total soluble solids ( $\left.{ }^{\circ} \mathrm{Brix}\right), \mathrm{pH}$, titratable acidity (\%), color, turbidity (NTU), absorbance coefficient $\left(\mathrm{cm}^{-1}\right)$, and ascorbic acid content $(\mathrm{g} / \mathrm{L})$ of treated and untreated FSWGJ were measured before and after UV processing, and also during the re- frigerated storage period. The $\mathrm{pH}$ and total soluble solids $\left({ }^{\circ} \mathrm{Brix}\right)$ were measured using a bench top $\mathrm{pH}$ meter (HANNA Instruments, Ann Arbor, MI, U.S.A.) and refractometer (MettlerToledo RE40D; Mettler Toledo, LLC, Columbus, OH, U.S.A.), respectively.

The absorbance of FSWGJ samples were measured using a UVvisible spectrophotometer (Carry 100; Varian Inc.) set at a wavelength of $254 \mathrm{~nm}$. A variety of dilution factors were applied (1:50, $1: 100,1: 250,1: 500$, and 1:1000). The absorbance coefficient $\left(A_{\mathrm{e}}\right)$ was estimated from the slope of absorbance versus sample concentration plot (Unluturk and others 2010). The turbidity of the grape juice samples was determined by means of a turbidimeter $(\mathrm{HACH}$ 2100AN IS; HACH Company, Loveland, CO, U.S.A.). Results were given as Nephelometric Turbidity Unit (NTU). CIE color parameters, for example, $L^{*}$ (brightness-darkness), $a^{*}$ (rednessgreenness), $b^{*}$ (yellowness-blueness), were measured by a chromometer (Konica Minolta CR 400 Chromometer; Konica Inc., Tokyo, Japan). Total color difference $(\Delta E)$ and browning index (BI) (Palou and others 1998) of the samples were calculated from the Eq. (4) and (5):

$$
\begin{gathered}
\Delta E=\sqrt{\left(\Delta L^{*}\right)^{2}+\left(\Delta a^{*}\right)^{2}+\left(\Delta b^{*}\right)^{2}} \\
\mathrm{BI}=100 * \frac{\frac{\left(a^{*}+1.75 L^{*}\right)}{\left(5.645 L^{*}+a^{*}-3.012 b^{*}\right)}-0.31}{0.172}
\end{gathered}
$$

Titratable acidity of treated and untreated FSWGJ was determined by titrating $10 \mathrm{~mL}$ juice sample with $0.1 \mathrm{~N} \mathrm{NaOH}$ and phenolphthalein as an indicator. Results were expressed as \% tartaric acid (AOAC, 1990). The ascorbic acid was determined by L-ascorbic acid test kit (Boehringer Mannheim-R-Biopharm, Roche, Germany), according to the manufacturer's protocol.

\section{Statistical analysis}

All the microbiological and the physicochemical analysis were carried out in triplicate. Inactivation data and physicochemical properties were presented as mean values \pm standard deviation. ANOVA and two sample $t$-test were carried out using the Minitab 16 (Minitab Inc., State College, Pa., U.S.A.), and differences were considered to be significant for $P \leq 0.05$.

\section{Results and Discussion}

\section{Inactivation study}

After application of 8 cycles (32.5 min of exposure time) and $1.24 \mathrm{~J} / \mathrm{cm}^{2} \mathrm{UV}$ dose/cycle (total UV dose of $9.92 \mathrm{~J} / \mathrm{cm}^{2}$ ) in the continuous flow UV reactor, $5.34 \pm 0.01 \log \mathrm{CFU} / \mathrm{mL}$ reduction was achieved for E. coli K-12 (ATCC 25253) suspended in FSWGJ, as shown in Figure 2. Since the penetration depth of UV light is very low in FSWGJ due to suspended particles, a very high dose of UV was applied in order to meet the FDA requirement. Because of the suspended particles, the turbidity and absorbance coefficients of FSWGJ (98.22 NTU and $12.13 \mathrm{~cm}^{-1}$ ) were higher than those for clarified white grape juice $(5.49 \mathrm{NTU}$ and $5.82 \mathrm{~cm}^{-1}$ ) (Baysal and others 2013). Considering these optical properties, compared with the clear juice, the turbid juice needs to be subjected to a higher UV dose in order to achieve similar log reductions. In fact, Murakami and others (2006) observed a decrease in UV inactivation efficiency of $E$. coli K-12 with an increase in suspended particles in turbid apple juice. Koutchma and others (2004) treated clear apple juice to inactivate E. coli K-12 
by continuous flow UV reactor applying $14.5 \mathrm{~mJ} / \mathrm{cm}^{2}$ of $U V$ dose and achieved 3 to $4 \log \mathrm{CFU} / \mathrm{mL}$ of inactivation. In contrast, they obtained $<1 \log \mathrm{CFU} / \mathrm{mL}$ of reduction for $E$. coli $\mathrm{K}-12$ in high turbid apple juice at a dosage of $21.5 \mathrm{~mJ} / \mathrm{cm}^{2}$. The inactivation efficiency of $E$. coli K-12 was directly affected by different physical and chemical properties of turbid and clear apple juices.

Additionally, Koutchma and others (2006) applied UV light to apple cider to inactivate E. coli $\mathrm{K}-12$ using laminar flow and turbulent flow UV systems. The authors stated that UV dose ranges between 90 and $150 \mathrm{~mJ} / \mathrm{cm}^{2}$ were necessary for a decimal reduction in turbulent UV reactor system at flow rate of 1250 $\mathrm{mL} / \mathrm{s}$. Nonetheless, UV dose in the range of 18.8 to $25.1 \mathrm{~mJ} / \mathrm{cm}^{2}$ was required in the thin film laminar UV reactor for one decimal reduction at a flow rate of $56.8 \mathrm{~mL} / \mathrm{s}$. The authors determined that turbulent flow was not appropriate for high turbid fruit juices such as apple cider, and recommended effective mixing in the UV systems in the treatment of these types of fruit juices.

In the current work, the penetration depth and absorbance coefficient were also found to be very important for the inactivation efficiency of the UV system. Caminiti and others (2012) applied $53.1 \mathrm{~J} / \mathrm{cm}^{2}$ of UV dose for reconstituted apple juice using UV rising film tubular reactor. They observed $>5 \log$ reduction in the number of E. coli K-12. Their system had an annular space gap of $1.6 \mathrm{~mm}$, considered by smaller than the one used in this study
$(5 \mathrm{~mm})$, and therefore provided better inactivation efficiency. On the other hand, the reconstituted apple juice had a relatively low absorbance coefficient at $254 \mathrm{~nm}\left(5.81 \mathrm{~cm}^{-1}\right)$ compared with turbid FSWGJ $\left(12.13 \mathrm{~cm}^{-1}\right)$ revealing that UV light penetration was low in turbid FSWGJ. In another study, Geveke and Torres (2012) examined UV inactivation of E. coli K-12 in grapefruit juice using centrifugal continuous flow UV reactor. They applied $19 \mathrm{~mJ} / \mathrm{cm}^{2}(2.6 \mathrm{~J} / \mathrm{mL})$ of $\mathrm{UV}$ dose and achieved $5.1 \log \mathrm{CFU} / \mathrm{mL}$ of reduction in the number of E. coli K-12. It was possible to achieve a high inactivation rate with a low UV dose level due to the good penetration of UV light in the thin film generated by centrifugation.

\section{Shelf life study}

Microbiological quality of FSWGJ. Logarithmic changes in yeast, LAB and total aerobic counts of untreated and UV$\mathrm{C}$ treated FSWGJ samples during storage at $4{ }^{\circ} \mathrm{C}$ are shown in Figure 3. The deterioration of UV-C treated and untreated samples was due to yeast and LAB growth during storage. It was found that the microbial and sensorial quality of the fruit juice were acceptable by consumers when the total microbial count was less than $5000 \mathrm{CFU} / \mathrm{mL}$ (Tran and Farid 2004). Hence, microbiological and physicochemical tests were stopped after $14 \mathrm{~d}$ because the total microbial count was over $5000 \mathrm{CFU} / \mathrm{mL}$ after this time.

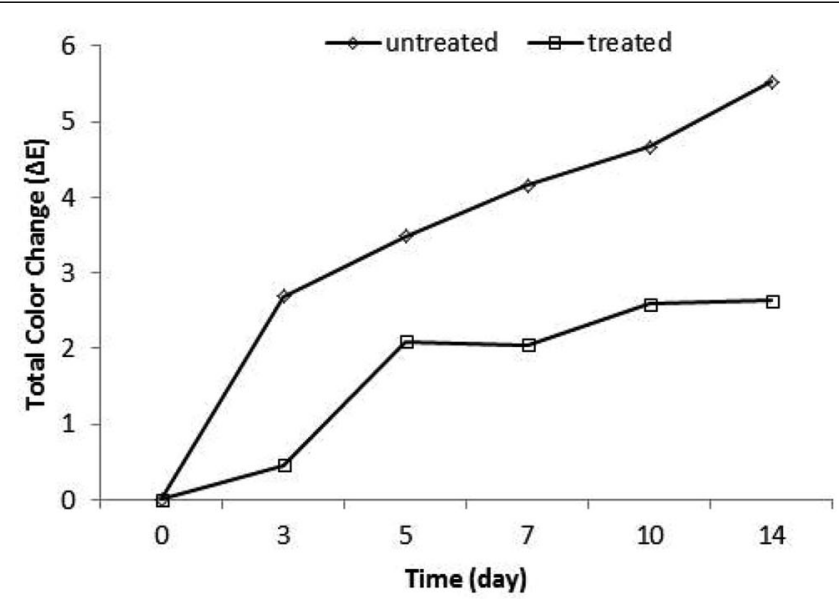

Figure 7-Changes in (A) color and (B) ascorbic acid content of UV-C treated and untreated FSWGJ during storage at $4{ }^{\circ} \mathrm{C}$ for $14 \mathrm{~d}$ (error bars are standard deviation of the mean of three experiments. Where error bars are not displayed, they are smaller than the graph symbol).

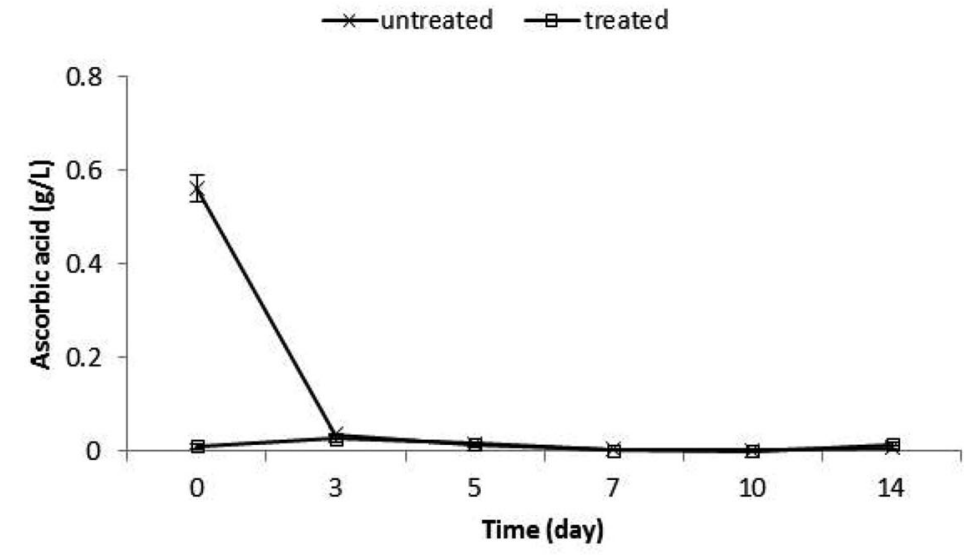


Initially, untreated FSWGJ had $1.35 \pm 0.07 \log \mathrm{CFU} / \mathrm{mL}$ of yeast and $1.08 \pm 0.21 \log \mathrm{CFU} / \mathrm{mL}$ of LAB. UV-C treated samples had no background flora. In the UVC treated juice, no yeast, LAB or total aerobic bacteria growth was seen in the 1 st $5 \mathrm{~d}$. The yeast, $\mathrm{LAB}$ and total aerobic count of treated juice samples started to increase after the 5 th $\mathrm{d}$ of storage. Meanwhile, the same trend was observed in the untreated samples after the $3 \mathrm{rd} \mathrm{d}$ of storage. The microbial growth in untreated FSWGJ samples was detected to be higher than that of UV-C treated samples. Nonetheless, UV-C treated samples reached the spoilage limit in relation to yeast count after $14 \mathrm{~d}$ storage. UV treatment was therefore able to increase microbial shelf life of FSWGJ by two fold. Similarly, Feng and others (2013) extended the shelf life of watermelon juice up to $31 \mathrm{~d}$, by means of a UV treatment using helix Teflon ${ }^{\circledR}$-coil UV-C reactor. Torkamani and Niakousari (2011) investigated microbial shelf life of UV-C treated orange juice and reported that the shelf life of orange juice was extended for $7 \mathrm{~d}$ as a result of exposure to UV light.

Physicochemical properties of FSWGJ. Physicochemical and optical properties of FSWGJ before and after UV treatment and at the end of the storage period were shown in Table 1. There were no significant differences in $\mathrm{pH}$, total soluble content and total titratable acidity values after UV-C treatment compared to untreated samples $(P>0.05)$. Other studies in the literature showed no significant changes in $\mathrm{pH}$, soluble solids and titratable acidity values of juices after UV-C treatment (Caminiti and others 2012; Pala and Toklucu 2011, 2013a; Tran and Farid 2004).

On the other hand, $\mathrm{pH}$ slightly decreased both in the treated and untreated grape juice samples during $14 \mathrm{~d}$ of storage (Figure 4A). The change of $\mathrm{pH}$ in untreated juice samples was more pronounced in comparison with irradiated samples (Table 1). Similarly, Feng and others (2013) observed a marked decrease in $\mathrm{pH}$ for untreated watermelon juice during storage period. In contrast, Donahue and others (2004) found no significant changes on $\mathrm{pH}$ of $\mathrm{UV}-\mathrm{C}$ treated apple cider during storage. The change in $\mathrm{pH}$ was due to the increase of acidity caused by the metabolic activity of microorganisms during the storage period. Nualkaekul and Charalampopoulos (2011) observed a decrease in $\mathrm{pH}$ values of orange, grapefruit, blackcurrant, pomegranate, cranberry, and lemon juice, whereas the lactic acid and acetic acid amounts increased with storage time, suggesting microorganisms metabolizing available energy sources.

A significant decrease was observed in the total soluble solid content $\left({ }^{\circ}\right.$ Brix $)$ of treated and untreated juice samples with increased storage time, compatible with results for growth patterns of microorganisms in juice during storage (Figure 4B). Chia and others (2012) reported a decrease in the total soluble solids for untreated and UV-C treated pineapple juice samples throughout storage. It was speculated that the change in total soluble solids is the result of the microbial activity that cause sugar fermentation (Chia and others 2012; Rivas and others 2006; Rosen and Gothard 2010). Titratable acidity level was increased during storage period, supporting the results obtained for $\mathrm{pH}$ (Figure 4C).

Changes in turbidity and absorbance coefficient of UV-C treated and untreated FSWGJ after the treatment and during storage at $4{ }^{\circ} \mathrm{C}$ for $14 \mathrm{~d}$ were shown in Figure 5 and Table 1 . The turbidity in untreated samples was significantly $(P<0.05)$ less than turbidity of FSWGJ subjected to UV-C treatment. One possible reason for this may be the reduction in microbial counts in grape juice resulting from exposure to UV light. There was a marked increase in turbidity values of FSWGJ samples after the 7th $\mathrm{d}$ of storage at $4{ }^{\circ} \mathrm{C}$ (Figure $5 \mathrm{~A}$ ). In contrast, in the untreated samples, there was a gradual increase in turbidity, with samples becoming cloudier upon the increase in microbial count from the beginning of the storage period.

Similarly, Tandon and others (2003) observed a significant change in turbidity of UV-C-irradiated $\left(14 \mathrm{~mJ} / \mathrm{cm}^{2}\right.$ at $\left.254 \mathrm{~nm}\right)$ apple cider during storage. Chia and others (2012) also stated that the increasing of yeast and bacteria contributed to the turbidity of UV-irradiated and thermally pasteurized pineapple juices during storage period. Overall, it was claimed that an increase in turbidity during storage time was due to an increase in the amount of spoilage yeast and bacteria producing visible sediment and cloud in juice products (Chia and others 2012; Digiacomo and Gallagher 1959; Tandon and others 2003).

The absorbance coefficient of untreated grape juice decreased throughout the storage period, while the absorbance coefficient of UV-C treated samples increased from $7.69 \pm 0.16 \mathrm{~cm}^{-1}$ to $12.95 \pm 3.58 \mathrm{~cm}^{-1}$ (Table 1 and Figure $5 \mathrm{~B}$ ). This was probably due to the degradation of color compounds by UV-C treatment, causing an increase in the turbid structure. The high absorption coefficient is due to presence of the polymeric fruit derivatives, for example, melanin and melanoidin, which are responsible for the brown color of fruit juice. The literature has reported the absorptivity property of melanoidin pigments during UV-C inactivation of various enzymes (Seiji and Iwashita 1965). The results of the experiments revealed that the degradation of melanoidins occurred by long exposure of the fruit juice samples to UV-C light (Ibarz and others 2005).

In the present study, significant change was observed in the BI value of treated samples $(P<0.05)$ by the UV-C treatment (Table 1). This was because significant effects of UV-C irradiation was observed in the brightness $\left(L^{*}\right)$, redness $\left(a^{*}\right)$, and yellowness $\left(b^{*}\right)$ of the FSWGJ samples $(P<0.05)$ (Table 1$)$. In fact, Guerrero-Beltrán and Barbosa-Cánovas (2005) observed a significant decrease in the $a^{*}$ and $b^{*}$ values of apple juice samples after UV-C irradiation. On the other hand, Ibarz and others (2005) showed an increase in brightness $\left(L^{*}\right)$, but a significant decrease in redness-greenness $\left(a^{*}\right)$ and yellowness-blueness $\left(b^{*}\right)$ when apple, peach and lemon juices were exposed to UV light in the wavelength range of 250 to $650 \mathrm{~nm}$. They claimed that the changes of color attributes of apple juice were due to melanins and melanoidin destruction caused by exposure to UV-C light. The results of this study indicate that there was a photo-degradation of juice pigments due to long contact time (32.5 min) with UV light.

Storage time had a significant $(P<0.05)$ effect on the $L^{*}, a^{*}$, and $b^{*}$ values of both treated and untreated grape juice samples (Figure 6 and Table 1). As a result, the BI value of untreated and treated samples was increased during storage period. The $\Delta E$ value of UV treated samples increased with storage time and became "noticeable" $(1.5<\Delta E<3.0)$ at the end of storage period $(14 \mathrm{~d})$, whereas dramatic changes in $\Delta E$ of untreated juice samples observed throughout the whole storage period (Figure 7 and Table 1). $L^{*}$ values of the UV-C treated and untreated samples decreased during the storage period (Figure 6A). The same trend was observed in the other studies (Aguilo-Aguayo and others 2009; Chia and others 2012; Genovese and others 1997; Ibarz and others 2005). These studies also showed that the brightness $\left(L\right.$ value) of juices decreased during storage at $4{ }^{\circ} \mathrm{C}$. The value of $a^{*}$, which reflects redness, was significantly increased through the end of $14 \mathrm{~d}$ of storage in both samples $(P<0.05)$ (Figure 6B). The yellowness, or $b^{*}$ value, of UV-C treated and untreated samples initially increased during the $5 \mathrm{~d}$ storage period, but remained largely unchanged after this time (Figure 6C). The yellowness $\left(b^{*}\right)$ 
and redness $\left(a^{*}\right)$ of treated juices was significantly $(P<0.05)$ lower than for untreated juices at the end of storage period (Table 1). Changes in color parameters in FSWGJ upon exposure to UVC light and during storage period were attributed to the degradation of colored pigments due to the high UV irradiation dose (Chia and others 2012; Ibarz and others 2005).

Changes in contents of ascorbic acid as a function of storage time and UV treatment are provided in Figure 7 and Table 1. UV$\mathrm{C}$ treatment significantly degraded the ascorbic acid content of FSWGJ $(P<0.05)$ (Table 1). A marked decrease was observed in ascorbic acid content of untreated FSWGJ on the 3rd d of storage, and continued to diminish after this time (Figure 7). No ascorbic acid remained by the end of storage period. Similarly, Chia and others (2012) also observed significant decrease in the ascorbic acid content of untreated and UV-C treated pineapple juice. Davey and others (2000) reported ascorbic acid degradation due to UV-C exposure, Shaw and others (1992a,1992b) investigated the effect of storage on the ascorbic acid content of stored fresh mandarin and orange fruits; at the end of their shelf life, $50 \%$ retention of the initial ascorbic acid content was reported. In other studies, the degradation of ascorbic acid during storage has been attributed to atmospheric oxygen (Odriozola-Serrano and others 2008), and various factors such as light exposure, hydrogen peroxides, storage temperature, type of processing and packaging materials used, and enzymes present (ascorbate oxidase and peroxidase) (Ayhan and others 2001; Davey and others 2000).

\section{Conclusions}

The shelf life of grape juice was determined as $14 \mathrm{~d}$ for UV-C treated FSWGJ. Untreated white grape juice samples were spoiled on the 7 th $\mathrm{d}$ of storage. Thus it can be concluded that the microbial shelf life of FSWGJ was increased by 2 -fold. Although the microbial shelf life of FSWGJ doubled, the quality of juice was adversely affected. The quality of juice can be preserved by increasing the flow rate in the UV-C treatment of grape juice thus decreasing the contact time between UV-C light and the grape juice. Otherwise, the required microbial safety with minimal impact on physicochemical and nutritive properties can be most effectively achieved by combinations of different non-thermal treatments (for example, US, PEF, HPP, and so on), exploiting the hurdle effect. It is therefore important to conduct further research on hurdle technology, an alternative approach which maximizes microbial inactivation and extends the shelf life of freshly squeezed juice products.

\section{Acknowledgment}

This study was supported by the Dept. of Food Engineering, Izmir Inst. of Technology, Izmir, Turkey (2010IYTE09). The authors declare that there are no conflicts of interest.

\section{References}

Aguilo-Aguayo I, Oms-Oliu G, Soliva-Fortuny R, Martín-Belloso O. 2009. Changes in quality attributes throughout storage of strawberry juice processed by high-intensity pulsed electric fields or heat treatments. Food Sci Technol 42:813-8.

Alongi KS, Padilla-Zakour OI, Sacks GL. 2010. Effects of concentration prior to coldstabilization on anthocyanin stability in concord grape juice. J Agric Food Chem 58:11325-32 AOAC 1990. Official methods for analysis. 15th Edn. Associacion of Official Agricultura Chemists, Washington, DC.

Ayhan Z, Yeom HW, Zhang QH, Min DB. 2001. Flavor, color, and vitamin C retention of pulsed electric field processed orange juice in different packaging materials. J Agric Food Chem 49:669-74.

Baysal, AH, Molva C, Unluturk S. 2013. UV-C light inactivation and modeling kinetics of Alicyclobacillus acidoterrestris spores in white grape and apple juices. Int J Food Microbio $166: 494-8$.

Bird RB, Steward WE, Lightfood EN. 2002. Transport phenomena. $3^{\text {rd }}$ Edition. New York: John Wiley Sons, Inc. p. 53-6.
Cielo DC, Mitilinaki E, Guerrero SN, Alzamora SM. 2010. Use of high-intensity ultrasound and UV-C light to inactivate some microorganisms in fruit juices. Food Bioprocess Technol 3:797-803.

Caminiti I, Palgan I, Muñoz A, Noci F, Whyte P, Morgan D, Cronin D, Lyng J. 2012. The effect of ultraviolet light on microbial inactivation and quality attributes of apple juice. Food Bioprocess Technol 5(2):680-6.

Chia SL, Rosnah S, Noranizan MA, Wan Ramli WD. 2012. The effect of storage on the quality attributes of ultraviolet-irradiated and thermally pasteurised pineapple juices. Int Food Res J 19(3):1001-10.

Choi LH, Nielsen SS. 2005. The effect of thermal and non-thermal processing methods on apple cider quality and consumer acceptability. J Food Quality 28:13-29.

Daoudi L, Quevedo JM, Trujillo J, Capdevila F, Bartra E, Mínguez S, Guamis B. 2002. Effects of high-pressure treatment on the sensory quality of white grape juice. High Pressure Res 22:705-9.

Davey MW, VanMontagu M, Inze D, Sanmartin M, Kanellis A, Smimoff N, Benzie LJJ, Strain JJ, Favell D, Fletcher J. 2000. Plant L-ascorbic: chemistry, function, metabolism, bioavailable and effects of processing. J Sci Food Agric 80(7):825-60.

Digiacomo R, Gallagher P. 1959. Soft drinks. In Downes, F.P and Ito, K. (Eds). Compedium of methods for the microbiological examination of foods. Washington D.C.: American Public Health Association. p 569-71

Donahue DW, Canitez N, Bushway AA. 2004. UV inactivation of E. coli O157:H7 in apple cider: Quality, sensory and shelf life analysis. J Food Process Preservation 28:368-87.

Feng M, Ghafoor K, Seo B, Yan K, Park J. 2013. Effects of ultraviolet-C treatment in Teflon ${ }^{\circledR}$ coil on microbial populations and physico-chemical characteristics of watermelon juice. Innov Food Sci Emerging Technol 19:133-9.

Frankel E N, Bosanek CA, Meyer AS, Silliman K, Kirk LL. 1998. Commercial grape juice inhibit the in vitro oxidation of human low-density lipoproteins. J Agric Food Chem 46:834

Franz CMAP, Specht I, Cho G, Graef V, Stahl MR. 2009. UV-C-Inactivation of microorganisms in naturally cloudy apple juice using novel inactivation equipment based on dean vortex technology. Food Control 20:1103-7.

Fredericks IN, Du Toit M, Krügel M. 2011. Efficacy of ultraviolet radiation as an alternative technology to inactivate microorganisms in grape juices and wines. Food Microbiol 28:510-7. Gabriel AA, Nakano H. 2009. Inactivation of Salmonella, E. coli and Listeria monocytogenes in phosphate-buffered saline and apple juice by ultraviolet and heat treatments. Food Control 20:443-6.

Genovese DB, Elustondo MP, Lozano JE. 1997. Color and cloud stabilization by steam heating during crushing in cloudy apple juice. J Food Sci 62:1171-5.

Geveke DJ, Torres D. 2012. Pasteurization of grapefruit juice using a centrifugal ultraviolet light irradiator. J Food Eng 111:241-6.

Guerrero-Beltrán JA, Barbosa-Cánovas GV. 2005. Reduction of Saccharomyces cerevisiae, Escherichia coli, and Listeria innocua in apple juice by ultraviolet light. J Food Process Eng 28:437-52.

Guerrero-Beltrán JÁ, Welti-Chanes J, Barbosa-Cánovas GV. 2009. Ultraviolet-C light processing of grape, cranberry and grapefruit juices to inactivate Saccharomyces cerevisiae. J Food Process Eng 32:916-32.

Heinz V, Toepfl S, Knorr D. 2003. Impact of temperature on lethality and energy efficiency of apple juice pasteurization by pulsed electric fields treatment, Innov Food Sci Emerg Technol 4(2):167-75.

barz A, Pagán J, Panadés R, Garza S. 2005. Photochemical destruction of color compounds in fruit juices. J Food Eng 69:155-60.

Keyser M, Muller I, Cilliers FP, Nel W, Gouws PA. 2008. UV Radiation as a non-therma treatment for the inactivation microorganisms in fruit juice. Innov Food Sci Emerg Technol 9(3):348-54

Koutchma T, Keller S, Parisi B, Chirtel S. 2004. Ultraviolet disinfection of juice products in laminar and turbulent flow reactors. Innov Food Sci Emerg Technol 5:179-89.

Koutchma T, Parisi B, Unluturk SK. 2006. Evaluation of UV dose in flow-through reactors for fresh apple juice and cider. Chem Eng Commun 193:715-28.

Koutchma T. 2009. Advances in ultraviolet light technology for non-thermal processing of liquid foods. Food Bioprocess Technol 2(2):138-55.

Lee HS, Coates GA. 2003. Effect of thermal pasteurization on Valencia orange juice color and pigments. LWT-Food Sci Technol 36(1):153-6.

Mazzotta AS. 2001. Thermal inactivation of stationary-phase and acid-adapted Escherichia coli O157:H7, Salmonella, and Listeria monocytogenes in fruit juices. J Food Protect 64(3):31520

Mertens B, Knorr D. 1992. Developments of non-thermal processes for food preservation. Food Technol 46:124-33.

Morowitz HJ. 1950. Absorption effects in volume irradiation of microorganisms. Science 111:229-30.

Murakami EG, Jackson L, Madsen K, Schickedanz B. 2006. Factors affecting the ultraviolet inactivation of Escherichia coli K-12 in apple juice and a model system. J Food Process Eng 29:53-71.

Nualkaekul S, Charalampopoulos D. 2011. Survival of Lactobacillus plantarum in model solutions and fruit juices. Int J Food Microbiol 146:111-7.

Odriozola-Serrano I, Aguiló-Aguayo I, Soliva-Fortuny R, Gimeno-Anó V, Martín-Belloso O. 2008. Lycopene, vitamin C, antioxidant capacity of tomato juice as affected by high-intensity pulsed electric fields critical parameters. J Agric Food Chem 55 (22):9036-42.

Pala CU, Toklucu AK. 2011. Effect of UV-C light on anthocyanin content and other quality parameters of pomegranate juice. J Food Compos Anal 24(6):790-5

Pala CU, Toklucu AK. 2013a. Effects of UV-C light processing on some quality characteristics of grape juices. Food Bioprocess Technol 6:719-25.

Pala CU, Toklucu AK. 2013b. Microbial, physicochemical and sensory properties of UV-C processed orange juice and its microbial stability during refrigerated storage. LWT-Food Sci Technol 50(2):426-31

Palou E, López-Malo A, Barbosa-Cánovas GV, Welti-Chanes J, Davidson PM, Swanson BG. 1998. High hydrostatic pressure come-up time and yeast viability. J Food Protect 61:1657-60.

Patil S, Bourke P, Frias JM, Tiwari BK, Cullen PJ. 2009. Inactivation of Escherichia coli in orange juice using ozone. Innov Food Sci Emerg Technol 10:551-7.

Rahn RO. 1997. Potassium iodide as a chemical actinometer for $254 \mathrm{~nm}$ radiation: Use of iodate as an electron scavenger. Photochem Photobiol 66(4):450-5. 
Rahn RO, Stefan MI, Bolton JR, Goren E, Shaw P, Lykke KR. 2003. Quantum yield of the iodide-iodate chemical actinometer: Dependence on wavelength and concentration. Photochem Photobiol 82:611-5.

Rahn RO, Bolton JR, Stefan MI. 2006. The iodide/iodate actinometer in UV disinfection: Determination of the fluence rate distribution in UV reactors. Photochem Photobiol 78(2):14652.

Rivas A, Rodrigo D, Martinez A, Barbosa-Canovas GV, Rodrigo M. 2006. Effect of PEF and heat pasteurization on the physical-chemical characteristics of blended orange and carrot juice. Food Sci Technol 39:1163-70.

Rosen J, Gothard LQ. 2010. Encyclopedia of physical science. Volume 1. New York: Infobase Publishing.

Seiji M, Iwashita S. 1965. Enzyme inactivation by ultraviolet light and protective effect of melanin. J Biochem 57:457.

Shaw PE, Moshonas M, Nisperos-Carriedo MO. 1992a. Controlled atmosphere storage effect on the composition of volatile components in dancy mandarin and mandarin hybrid fruit. LWT-Food Sci Technol 25:346-9.

Shaw PE, Moshonas M, Nisperos-Carriedo M, Carter RD. 1992b. Controlled-atmosphere treatment of freshly harvested oranges at elevated temperature to increase volatile flavor components. J Agric Food Chem 40:1041-5.

Tandon K, Worobo RW, Churey JJ, Padilla-Zakour OI. 2003. Storage quality of pasteurized and UV treated apple cider. J Food Process Preserv 27:21-35.
Tikekar RV, Anantheswaran RC, Laborde LF. 2011. Ascorbic acid degradation in a model apple juice system and in apple juice during ultraviolet processing and storage. J Food Sc $76(2): 62-71$.

Tiwari BK, O' Donnell CP, Muthukumarappan K, Cullen PJ. 2009. Anthocyanin and colour degradation in ozone treated blackberry juice. Innov Food Sci Emerg Technol 10: $70-5$.

Torkamani AE, Niakousari M. 2011. Impact of UV-C light on orange juice quality and shelf life. Int Food Res J 18(4):1265-8.

Tran MT, Farid M. 2004. Ultraviolet treatment of orange juice. Innov Food Sci Emerg Technol 5:495-502.

Unluturk S, Atilgan MR, Baysal AH, Tari C. 2008. Use of UV-C radiation as a non-thermal process for liquid egg products (LEP). J Food Eng 85(4):561-8.

Unluturk S, Atilgan MR, Baysal AH, Unluturk MS, 2010. Modeling inactivation kinetics of liquid egg white exposed to UV-C irradiation. Int J Food Microbiol 142(3):341-7.

Unluturk S, Atilgan MR. 2014. UV-C Irradiation of Freshly Squeezed Grape Juice and Modeling Inactivation Kinetics. J Food Process Eng. 37(4):438-49.

U.S. FDA. 2000. Irradiation in the production, processing and handling of food. Fed. Regist 2000, 21 CFR Part 179, 6571056-71058. 